\title{
BIOANALYTICAL METHOD DEVELOPMENT AND VALIDATION FOR THE DETERMINATION OF SOFOSBUVIR FROM HUMAN PLASMA
}

\author{
S. MADHAVI ${ }^{* 1}$, A. PRAMEELA RANI ${ }^{1}$ \\ ${ }^{1}$ University College of Pharmaceutical Sciences, Acharya Nagarjuna University, Nagarjuna Nagar, Guntur, Andhra Pradesh, India 522510 \\ Email: madhavitirumalesh@gmail.com
}

Received: 15 Nov 2016 Revised and Accepted: 09 Jan 2017

\begin{abstract}
Objective: This study points to build up and validate a simple methodology to quantify the most used drug sofosbuvir for the treatment of hepatitis $\mathrm{C}$ virus (HCV) infection, in human plasma by using atazanavir as an Internal Standard (IS) for preclinical studies and validate as per USFDA guidelines.

Methods: Sofosbuvir was isolated from plasma samples by liquid-liquid extraction method using acetonitrile; good chromatographic separation was achieved on Kromasil Column $(250 \mathrm{~mm} \times 4.6 \mathrm{~mm}, 5 \mu \mathrm{m})$. The mobile phase consisted of $0.1 \%$ orthophosphoric acid (OPA) buffer pH 2 and acetonitrile in the ratio of $(68: 32, \mathrm{v} / \mathrm{v})$, respectively. The analysis time was $7 \mathrm{~min}$ at a flow rate $1 \mathrm{ml} / \mathrm{min}$. The photodiode array detector (PDA) detection was carried out at $228 \mathrm{~nm}$. The suggested method was validated by performing linearity, system suitability, specificity and sensitivity, accuracy and precision, recovery, ruggedness, stability studies. The method was validated as per USFDA guidelines.
\end{abstract}

Results: The developed method resulted in retention times of sofosbuvir and IS were found out to be 4.7 and 4.2 min respectively. The calibration curves are linear ( $\mathrm{r} 2=0.999)$ over the concentration range of $0.050-2.0 \mu \mathrm{g} / \mathrm{ml}$ of plasma analytes concentration. LOQ value was found to be 0.050 $\mu \mathrm{g} / \mathrm{ml}$ with precision and accuracy. Within-batch \% mean accuracy of the method ranged between $96.00 \%$ and $109.09 \%$, and within-batch and total precision, expressed as the coefficient of variation, was 1.40-10.33\%. Overall percentage mean recovery of sofosbuvir from spiked plasma was $84.14 \%$. All the validated parameters were found to be within the limit.

Conclusion: A simple, accurate, precise, linear, rugged and rapid RP-HPLC method was developed for quantitative estimation of sofosbuvir in human plasma and should be suitable for conducting pharmacokinetics studies and therapeutic drug monitoring.

Keywords: Sofosbuvir, Human plasma, RP-HPLC, Method development, Validation, Liquid-liquid extraction

(c) 2016 The Authors. Published by Innovare Academic Sciences Pvt Ltd. This is an open access article under the CC BY license (http://creativecommons.org/licenses/by/4. 0/)

DOI: http://dx.doi.org/10.22159/ijpps.2017v9i3.16185

\section{INTRODUCTION}

Sofosbuvir is a prodrug nucleotide analogue used as a portion of combination therapy to treat hepatitis $\mathrm{C}$ virus (HCV) infection or to handle co-infection of HIV and HCV its function has also proven successful in the treatment of HCV in patients co-infected with HIV [1].

In 2013, the FDA approved sofosbuvir in combination with ribavirin (RBV) for dual oral therapy of HCV genotypes 2 and 3, and for triple therapy with injected pegylated interferon (peg IFN) and RBV for treatment-naive patients with HCV genotypes 1 and 4. In 2014, a combination of sofosbuvir with the viral NS5A inhibitor ledipasvir was approved. Recently, a new treatment, which is a combination of two direct-acting antiviral agents, ledipasvir $90 \mathrm{mg}$ (anti-NS5A) and sofosbuvir $400 \mathrm{mg}$ (anti-NS5B), has been approved in the US and the European Union for the treatment of chronic hepatitis $C$ viral infection [2].

The literature survey revealed that very few analytical methods reported for estimation of sofosbuvir, in single and combination, RPHPLC [3-5], bio-analytical UPLC-ESI-MS/MS method [6], in rat plasma by UPLC-MS/MS for quantification of sofosbuvir and its metabolites [7], UHPLC-MS/MS method [8]. The primary goal of this work was to produce a simple, sensitive, specific and economic bioanalytical RP-HPLC-PDA detection method for the determination of sofosbuvir from human plasma that is applicable in further pharmacokinetics studies. HPLC coupled with a PDA detector offers a cost effective bio-analytical method [9]. The developed method was validated according to USFDA guidelines [10].

The proposed research work describes the estimation of sofosbuvir in human plasma by reverse phase high-performance liquid chromatography (RP-HPLC) with PDA detection using atazanavir as an internal standard (IS). A widely practiced technique of composition involves the addition of an internal standard to correct for various analytic errors. In this approach, a known compound of a fixed concentration is in addition to the known amount of the sample to give a separate peak in the chromatogram to compensate for the losses of the compound of interest during the sample pre-treatment steps. It must accept a completely resolved peak with no hitches; it must not be present in the original sample. It must be stable, unreactive with sample components. In this method, atazanavir has used an internal standard as it doesn't interfere with the vertex area of sofosbuvir.

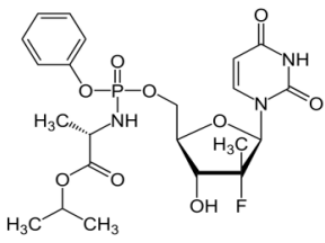

Fig. 1: Sofosbuvir structure [3]

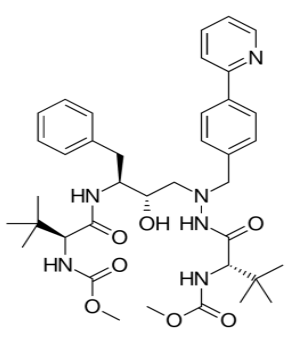

Fig. 2: Atazanavir structure [4] 


\section{MATERIALS AND METHODS}

\section{Instrumentation}

Chromatographic separation was performed on WATERS HPLC model: 2695, separation module, photodiode array detector model 2996, automatic injection, sampling vial 120 . The instrument was controlled using a computer via Empower-2 software. The mobile phase was filtered through a $0.45 \mu$ membrane filter and degassed for $30 \mathrm{~min}$. Analysis was performed at $30^{\circ} \mathrm{C}$ temperature.

\section{Chemicals and reagents}

The drugs sample of sofosbuvir, atazanavir obtained from Clearsynth Labs Limited (Mumbai, India). Acetonitrile, orthophosphoric acid (OPA) HPLC grade (Merck Ltd, Mumbai, India), HPLC grade water (Fisher Scientific, India), is used in the study. Pooled drug-free expired frozen human plasma (K2-EDTA as anticoagulant) was obtained from the St. Theresa Blood Bank, Hyderabad, was used during validation and study sample analysis. The plasma stored into- $70^{\circ} \mathrm{C} \pm 5^{\circ} \mathrm{C}$.

\section{Preparation of stock and intermediate working solutions of sofosbuvir}

The standard stock solution of sofosbuvir $(1.0 \mathrm{mg} / \mathrm{ml})$ was prepared in diluent (50: 50, acetonitrile: water). The standard working solution $(10 \mu \mathrm{g} / \mathrm{ml})$ was made by diluting the stock solution. Two separate stock solutions were prepared for the preparation of calibration curve standards (CC) and quality control samples (QC). The working solutions required for plotting calibration curve were also prepared in a diluent in a concentration range between $0.05-2.00 \mu \mathrm{g} / \mathrm{ml}$.

Calibration samples were prepared at a concentration of $0.05,0.10$ $0.15,0.5,0.75,1.0,1.6$ and $2.0 \mu \mathrm{g} / \mathrm{ml}$. Similarly, QC samples at the lower limit $(0.050 \mu \mathrm{g} / \mathrm{ml}, \mathrm{LLQC})$, low $(0.150 \mu \mathrm{g} / \mathrm{ml}, \mathrm{LQC})$ middle $(0.750 \mu \mathrm{g} / \mathrm{ml}, \mathrm{MQC})$, and high $(2.00 \mu \mathrm{g} / \mathrm{ml}, \mathrm{HQC})$ concentrations were prepared.

\section{Preparation of IS solution $(10 \mu \mathrm{g} / \mathrm{ml})$}

Accurately weighed $10 \mathrm{mg}$ of atazanavir taken in a $10 \mathrm{ml}$ volumetric flask and volume made up with diluent. From that stock solution, 0.1 $\mathrm{ml}$ of solution taken into a $10 \mathrm{ml}$ volumetric flask and the volume made up with diluent to produce a $10 \mu \mathrm{g} / \mathrm{ml}$ solution.

\section{Liquid-liquid extraction procedure}

A $250 \mu \mathrm{l}$ plasma sample, $10 \mu \mathrm{l}$ sofosbuvir and $50 \mu \mathrm{l}$ IS was placed into a centrifuge tube and $2 \mathrm{ml}$ of acetonitrile was added and allowed for cyclomixer for $30 \mathrm{Sec}$. Then vertexes for $2 \mathrm{~min}$ and finally centrifuged for $3 \mathrm{~min}$ at 3200 RPM speed. After centrifugation, the organic layer was collected and directly injected $10 \mu \mathrm{l}$ into the HPLC $[11,12]$. Calibration curves were prepared by linear regression analysis of the plot of the peak area against the concentration of sofosbuvir. The concentration of plasma samples was determined from the area of chromatography peak using the calibration curve.

\section{Preparation of the calibration curves}

Three calibration curves were prepared over the range of 0.05-2.0 $\mu \mathrm{g} / \mathrm{ml}$ sofosbuvir with individual calibration points of $0.05,0.10,0.15$, $0.5,0.75,1.0,1.6$ and $2.0 \mu \mathrm{g} / \mathrm{ml}$. The IS concentration was $10 \mu \mathrm{g} / \mathrm{ml}$.

\section{Validation}

The method was validated in accordance with USFDA guidelines. The validation parameters such as linearity and range, system suitability, Specificity, sensitivity, carry over, matrix effect, accuracy and precision (repeatability and reproducibility), recovery, ruggedness, and stability were evaluated.

\section{Linearity}

The linearity of the method was determined by using a $1 / x^{2}$ weighted least square regression analysis of standard plots associated with eight-point standard curve [13]. All the 3 calibration curves analysed were found to be linear for the standard concentration ranging from $0.05-2.0 \mu \mathrm{g} / \mathrm{ml}$

\section{System suitability}

A system suitability experiment was performed by injecting six consecutive injections using a standard aqueous mixture equivalent to MQC (Mid quality control sample) concentration of the calibration curve of sofosbuvir and $10 \mu \mathrm{g} / \mathrm{ml}$ for IS.

\section{Specificity and sensitivity}

The specificity of the HPLC method was established by screening the standard blanks of different lots of human plasma. The sensitivity of the method was evaluated by analyzing $6 \mathrm{LLOQ}$ samples $(0.050 \mu \mathrm{g} / \mathrm{ml})[14]$.

\section{Carryover}

Carryover is the appearance of an analyte signal in the blank sample after the analysis of samples with a high analyte concentration. As the HPLC system was equipped with autosampler injection mode, the carryover has been minimised. It was performed by injecting blank plasma sample immediately after the injection of ULOQ sample and studying the chromatogram of blank samples obtained.

\section{Accuracy and precision}

The accuracy of an analytical method describes the closeness of the determined value obtained by the method to the nominal concentration of the analyte (expressed in percentage). Accuracy should be assessed on samples spiked with known amounts of the analyte, quality control samples (QC samples).

The precision of the analytical method describes the closeness of repeated individual measures of the analyte. Precision is expressed as the coefficient of variation (CV). Precision should be demonstrated for the LLOQ, low, medium and high QC samples, within a single run and between different runs, i.e. using the same runs and data as for the demonstration of accuracy [15].

\section{Recovery}

The recovery is determined by comparing the analyte response in a biological sample that was spiked with the analyte and processed, with the response to a blank biological sample that was processed and then spiked with the analyte. Recovery is evaluated by replicating the analysis of at least 3 times each at 3 concentration levels (low, mid and high levels) [16].

\section{Ruggedness}

Ruggedness was performed by using different column and different analyst.

\section{Stability studies}

Long term shock stock solution stability for the sofosbuvir was determined at a concentration of LQC, HQC level using standard aqueous solution after a storage period of $37 \mathrm{~d}$ at $-28^{\circ} \mathrm{C}$ and -80 ${ }^{\circ} \mathrm{C}$ in the refrigerator. Stability was assessed by comparing the stability stock solution against the freshly prepared stock solution [17].

\section{RESULTS AND DISCUSSION}

\section{Chromatography optimization}

The mobile phase consisting of $0.1 \%$ orthophosphoric acid, acetonitrile (68: 32) was selected because it was found to give good separation for the peaks of sofosbuvir (Rt-4.78 min) and IS (Rt-4.2 $\mathrm{min}$ ) respectively. In addition to this, UV spectra of individual drugs were recorded in the wavelength range from 200 to $400 \mathrm{~nm}$ and the response for optimisation was compared. The choice of wavelength $228 \mathrm{~nm}$ was considered satisfactory, permitting the detection of sofosbuvir with adequate sensitivity.

\section{Linearity}

The method was validated over the range of $0.050-2.0 \mu \mathrm{g} / \mathrm{ml}$. By using calibration standards prepared by spiking drug Sofosbuvir and internal standard in plasma at different concentrations $0.01,0.05,0.1$, $0.5,1.0,2.0,5.0$ and $10.0 \mu \mathrm{g} / \mathrm{ml}$, the calibration graph was plotted taking a concentration of spiked plasma on $\mathrm{x}$-axis and area response ratio on y-axis (fig. 3.). Results were summarised in the table 1. 


\section{Specificity and sensitivity}

HPLC-PDA analysis of the blank human plasma samples showed no interference with both sofosbuvir and atazanavir (IS). The blank chromatogram is shown in fig. 4, indicating no interference in the sample at the retention time of $4.7 \mathrm{~min}$ for the drug sofosbuvir and at the retention time of $4.2 \mathrm{~min}$ for the IS. Sensitivity results were summarized in table 2 . In the plasma, the limit of quantification was found to be $0.05 \mu \mathrm{g} / \mathrm{ml}$ with accuracy and precision.

\section{Carryover test}

The carryover effect due to the autosampler was investigated by injecting a sequence of un-extracted (neat samples) and extracted samples. Results demonstrated that no significant carryover was observed during this experiment.

\section{System suitability test}

System suitability the $\% \mathrm{CV}$ of the retention times was found to be $\leq$ 0.48 for the analyte and IS. The \% $\mathrm{CV}$ of the peak area was found to be $\leq 1.11$ for the analyte and IS. Acceptance is limited for retention time (Rt) deviation and area deviation $2 \%$ and $5 \% \mathrm{CV}$ respectively were passed. The results were summarised in table 3.

\section{Accuracy and precision}

The within-batch the percentage mean accuracy ranged from 98.36 to $104.22 \%$. The between-batch or percentage mean accuracy was found to be 99.58 to $106.64 \%$. Within-batch precision, the \% CV, ranged from 1.4 to $10.33 \%$. The between-batch the $\% \mathrm{CV}$, ranged 5.71 to $9.00 \%$. The results were summarized in table 4 .

\section{Recovery}

The recovery was determined by comparing the aqueous solution and the spiked drug. The \% overall mean recovery of the drug and the internal standard was calculated and it was $84.14 \%$ and 80.96 $\%$ respectively. The results were summarized in the table 5 .

\section{Ruggedness}

The ruggedness of the method was carried out by changing by column and by a different analyst. The results were summarised in the table 6 .

\section{Long term shock stock solution stability studies}

Stability was assessed by comparing the stability of long-term shock stock solution at a temperature- $28{ }^{\circ} \mathrm{C}$ and $-80{ }^{\circ} \mathrm{C}$ for 37 days against the freshly prepared stock solution. The \% mean stability (at-28 ${ }^{\circ} \mathrm{C}$ ) of LQC and HQC sofosbuvir was found to be $101.78 \%$ and $102.39 \%$ respectively. The $\%$ mean stability (at$80^{\circ} \mathrm{C}$ ) of LQC and HQC sofosbuvir was found to be $101.89 \%$ and $100.78 \%$ respectively. The results were summarized in table 7 and 8.

The developed chromatographic method for the determination of sofosbuvir in human plasma was simple, precise, accurate and economical, as revealed by the statistical data of analysis. The internal standard used is readily available and economical. The mobile phase is simple to prepare and economical. The analytical assay of sofosbuvir was completed within 5.0 min revealing the rapidity of the proposed RP-HPLC method.

The linearity results showed that an excellent correlation existed between peak area and concentration of sofosbuvir within the concentration range tested. The values of slope and intercept of the calibration graph indicated the high reproducibility of the proposed method. Elevated values of correlation coefficient validated the linearity of the calibration plot and obedience to Beer's laws. Precision and accuracy results over 3 analytical batches are meeting the acceptance criteria. Overall percentage mean recovery is 84.14\%. The overall mean recovery \% CV for all QC levels less than $20.00 \%$. Recovery statistical data was found to be within limits. Sofobuvir was found to be stable as long term shock at $-28 \pm 5^{\circ} \mathrm{C}(37$ d) and $-80{ }^{\circ} \mathrm{C}(37 \mathrm{~d})$. When compared to previous bio-analytical methods [6-8], the developed method was simple, economical and accurate bio-HPLC method in human plasma.

Table 1: Linearity data of sofosbuvir

\begin{tabular}{|c|c|c|c|c|c|c|c|c|}
\hline \multirow[t]{6}{*}{ Acquisition batch ID } & Std1 & Std2 & Std3 & Std4 & Std5 & Std6 & Std7 & Std8 \\
\hline & \multicolumn{8}{|c|}{ Nominal concentration $(\mu \mathrm{g} / \mathrm{ml})$} \\
\hline & 0.050 & 0.100 & 0.150 & 0.500 & 0.750 & 1.000 & 1.600 & 2.000 \\
\hline & \multicolumn{8}{|c|}{ Nominal concentration range $(\mu \mathrm{g} / \mathrm{ml})$} \\
\hline & $0.040-0.060$ & $\begin{array}{l}0.085- \\
0.115 \\
\end{array}$ & $0.128-0.173$ & $\begin{array}{l}0.425- \\
0.575 \\
\end{array}$ & $0.638-0.863$ & $0.850-1.150$ & $1.360-1.840$ & $1.700-2.300$ \\
\hline & \multicolumn{8}{|c|}{ Back-calculated concentration $(\mu \mathrm{g} / \mathrm{ml})$} \\
\hline 1 & 0.050 & 0.098 & 0.154 & 0.501 & 0.762 & 0.921 & 1.568 & 1.961 \\
\hline 2 & 0.048 & 0.101 & 0.149 & 0.482 & 0.812 & 0.984 & 1.624 & 2.014 \\
\hline 3 & 0.053 & 0.096 & 0.150 & 0.528 & 0.701 & 1.110 & 1.701 & 1.981 \\
\hline Number of injections & 3 & 3 & 3 & 3 & 3 & 3 & 3 & 3 \\
\hline Mean & 0.0503 & 0.0983 & 0.151 & 0.5037 & 0.7583 & 1.005 & 1.6310 & 1.9853 \\
\hline SD & 0.00252 & 0.0025 & 0.0026 & 0.0231 & 0.0555 & 0.096 & 0.0667 & 0.02676 \\
\hline$\% \mathrm{CV}$ & 5.00 & 2.56 & 1.75 & 4.59 & 7.33 & 9.58 & 4.09 & 1.35 \\
\hline \%Mean accuracy & 100.67 & 98.33 & 100.67 & 100.73 & 101.11 & 100.5 & 101.94 & 99.27 \\
\hline
\end{tabular}

*Number of each concentration injections-3

Table 2: Sensitivity of sofosbuvir

\begin{tabular}{ll}
\hline Replicate no. & LLOQ (nominal concentration) $\mathbf{0 . 0 5 0} \boldsymbol{\mu g} / \mathbf{m l}$ \\
\cline { 2 - 2 } & Nominal concentration range $\mathbf{0 . 0 4 0 - 0 . 0 6 0} \boldsymbol{\mu g} / \mathbf{m l}$ \\
\hline 1 & Calculated concentration $(\boldsymbol{\mu g} / \mathbf{m l})$ \\
2 & 0.052 \\
3 & 0.045 \\
4 & 0.049 \\
5 & 0.058 \\
6 & 0.051 \\
Number of injections & 0.047 \\
Mean & 6 \\
SD & 0.0503 \\
$\%$ CV & 0.00455 \\
$\%$ Mean accuracy & 9.03 \\
\hline
\end{tabular}

*Number of injections-6 


\section{Acceptance criteria}

At least $67 \%$ (4 out of 6 ) of samples should be within 80.00$120.00 \%$.

$\%$ mean accuracy should be within 80.00-120 \%.

$\%$ CV accuracy should be $\leq 20.00 \%$

\section{Acceptance criteria}

The within and between batch precision for LQC, MQC and HQC should be $\leq 15.00 \%$ and for the LLOQ QC, it should be $\leq 20.00 \%$.

\section{Acceptance criteria}

$\% \mathrm{CV}$ of recovery at each QC level and for STD1 should be $\leq 15 \%$. The overall mean recovery $\% \mathrm{CV}$ for all QC levels should be $\leq 20.00 \%$.

Table 3: System suitability of sofosbuvir

\begin{tabular}{|c|c|c|c|c|c|}
\hline Sample name & Analyte area & Analyte retention time & IS area & IS retention time & Area ratio \\
\hline MQC1 & 123854 & 11.04 & 488297 & 9.21 & 0.2536 \\
\hline MQC2 & 123675 & 11.02 & 486375 & 9.21 & 0.2543 \\
\hline MQC3 & 125974 & 11.13 & 483712 & 9.27 & 0.2604 \\
\hline MQC4 & 125374 & 11.08 & 483754 & 9.52 & 0.2592 \\
\hline MQC5 & 123854 & 11.10 & 483697 & 9.20 & 0.2561 \\
\hline MQC6 & 123742 & 11.16 & 486421 & 9.25 & 0.2544 \\
\hline MEAN & & 11.089 & & 9.231 & 0.025633 \\
\hline SD & & 0.0524 & & 0.0291 & 0.002833 \\
\hline$\% \mathrm{CV}$ & & 0.047 & & 0.31 & 1.11 \\
\hline
\end{tabular}

*Number of injections-6

Table 4: Accuracy and precision

\begin{tabular}{|c|c|c|c|c|}
\hline \multirow[t]{5}{*}{ Acquisition batch ID } & HQC & MQC & LQC & LLOQ QC \\
\hline & \multicolumn{4}{|c|}{ Nominal concentration $(\mu \mathrm{g} / \mathrm{ml})$} \\
\hline & 2.000 & 0.750 & 0.150 & 0.050 \\
\hline & \multicolumn{4}{|c|}{ Nominal concentration range $(\mu \mathrm{g} / \mathrm{ml})$} \\
\hline & $1.700-2.300$ & $0.638-0.863$ & $0.128-0.173$ & $0.040-0.060$ \\
\hline \multicolumn{5}{|l|}{ Within batch data } \\
\hline B-1:Number of injections & 6 & 6 & 6 & 6 \\
\hline Mean & 1.9672 & 0.7670 & 0.1547 & 0.0515 \\
\hline SD & 0.09848 & 0.06297 & 0.01506 & 0.00532 \\
\hline$\% \mathrm{CV}$ & 5.01 & 8.21 & 9.73 & 10.33 \\
\hline \%Mean accuracy & 98.36 & 102.27 & 103.11 & 103.00 \\
\hline B-2:Number of injections & 6 & 6 & 6 & 6 \\
\hline Mean & 2.0195 & 0.8182 & 0.1505 & 0.0512 \\
\hline SD & 0.12761 & 0.03247 & 0.00896 & 0.00360 \\
\hline$\% \mathrm{CV}$ & 6.32 & 3.97 & 5.95 & 7.04 \\
\hline \%Mean accuracy & 100.98 & 109.09 & 100.33 & 102.33 \\
\hline B-3:Number of injections & 6 & 6 & 6 & 6 \\
\hline Mean & 1.9880 & 0.8143 & 0.1563 & 0.0480 \\
\hline SD & 0.114642 & 0.01140 & 0.01387 & 0.00438 \\
\hline$\% \mathrm{CV}$ & 7.37 & 1.40 & 8.87 & 9.13 \\
\hline \%Mean accuracy & 99.40 & 108.58 & 104.22 & 96.00 \\
\hline \multicolumn{5}{|l|}{ Between-batch data } \\
\hline $\mathrm{N}$ & 18 & 18 & 18 & 18 \\
\hline Mean & 1.9916 & 0.7998 & 0.1538 & 0.0502 \\
\hline SD & 0.12016 & 0.04569 & 0.01238 & 0.00452 \\
\hline$\% \mathrm{CV}$ & 6.03 & 5.71 & 8.05 & 9.00 \\
\hline \%Mean Accuracy & 99.58 & 106.64 & 102.56 & 100.44 \\
\hline
\end{tabular}

Table 5: Recovery data

\begin{tabular}{llllllll}
\hline Sofosbuvir & HQC & & MQC & & LQC & IS (10 $\boldsymbol{\mu g} / \mathbf{m l )}$ \\
\cline { 2 - 7 } & A & B & A & B & A & B & A \\
\hline Number of replicates & 6 & 6 & 6 & 6 & 6 & 6 \\
Mean & 284561 & 25879 & 155722 & 126194 & 40482 & 32572 \\
SD & 1578.01 & 4233.0 & 2982.4 & 2143.0 & 261.51 & 290.67 & 2835.42 \\
\%CV & 0.55 & 1.64 & 1.92 & 1.70 & 0.65 & 0.89 \\
\%Mean Recovery & 90.94 & & 81.04 & & 80.46 & \\
Overall\% Mean & 84.148 & & & & & \\
Recovery overall SD & 5.8929 & & & & & \\
overall \%CV & 7.00 & & & & & \\
\end{tabular}

*Number of injections-6, Unextracted response-A, Extracted response-B 
Table 6: Ruggedness data

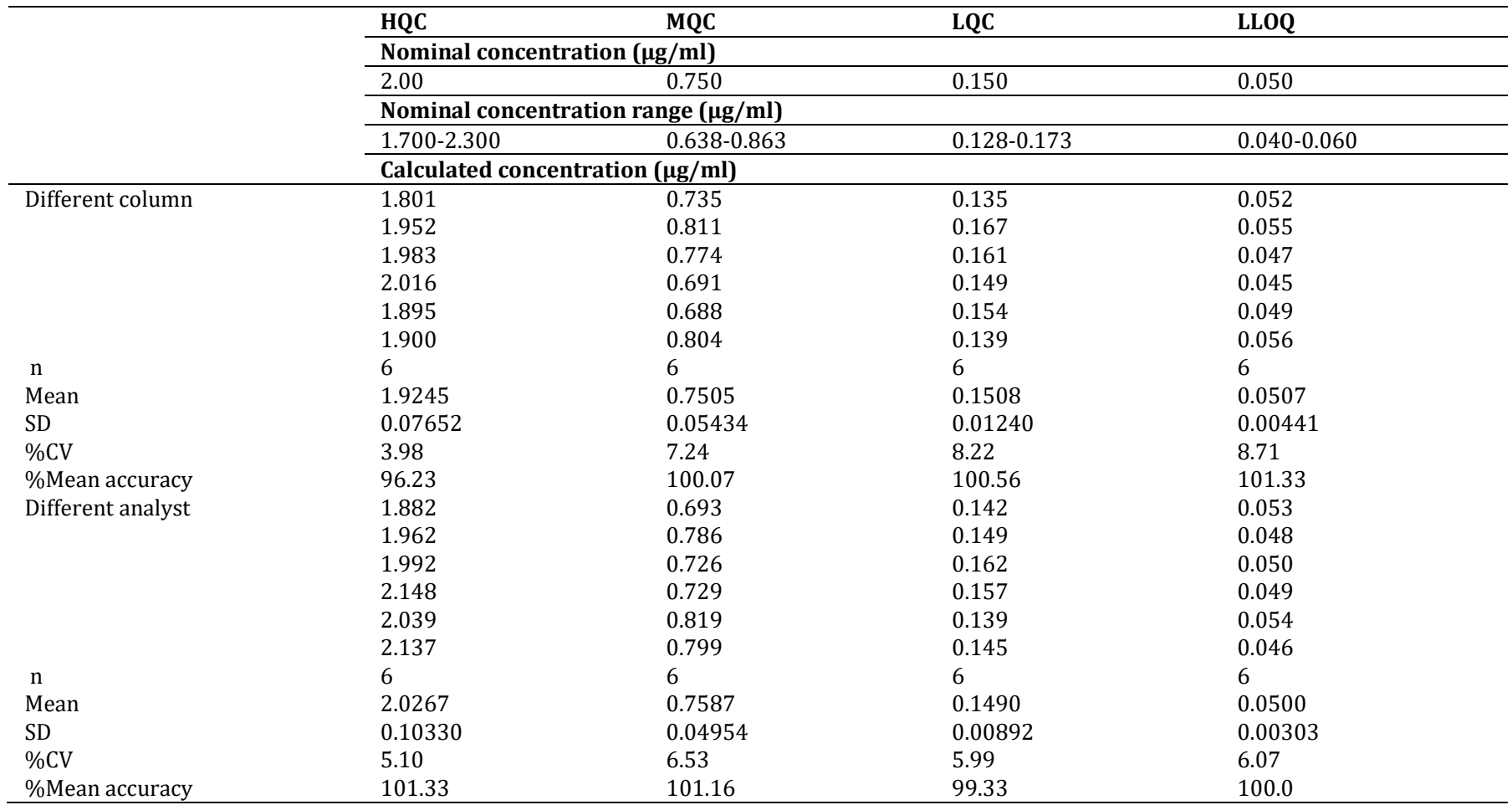

Table 7: Long-term stability study at-28 $\pm 5^{\circ} \mathrm{C}(37 \mathrm{~d})$

\begin{tabular}{|c|c|c|c|c|}
\hline \multirow[t]{6}{*}{ Replicate no. } & HQC & & LQC & \\
\hline & \multicolumn{4}{|c|}{ Nominal concentration $(\mu \mathrm{g} / \mathrm{ml})$} \\
\hline & 2.000 & & 0.150 & \\
\hline & \multicolumn{4}{|c|}{ Nominal concentration range $(\mu \mathrm{g} / \mathrm{ml})$} \\
\hline & \multicolumn{2}{|l|}{$1.700-2.300$} & \multicolumn{2}{|l|}{$0.128-0.173$} \\
\hline & Comparison sample & Stability sample & Comparison sample & Stability sample \\
\hline Number of replicates & 6 & 6 & 6 & 6 \\
\hline Mean & 1.9487 & 1.9952 & 0.1500 & 0.1527 \\
\hline SD & 0.11487 & 0.12951 & 0.01149 & 0.00807 \\
\hline$\% \mathrm{CV}$ & 5.89 & 6.49 & 7.66 & 5.28 \\
\hline$\%$ Mean accuracy & 97.43 & 99.76 & 100.0 & 101.78 \\
\hline$\%$ Mean stability & 102.39 & & 101.78 & \\
\hline
\end{tabular}

*Number of injections-6

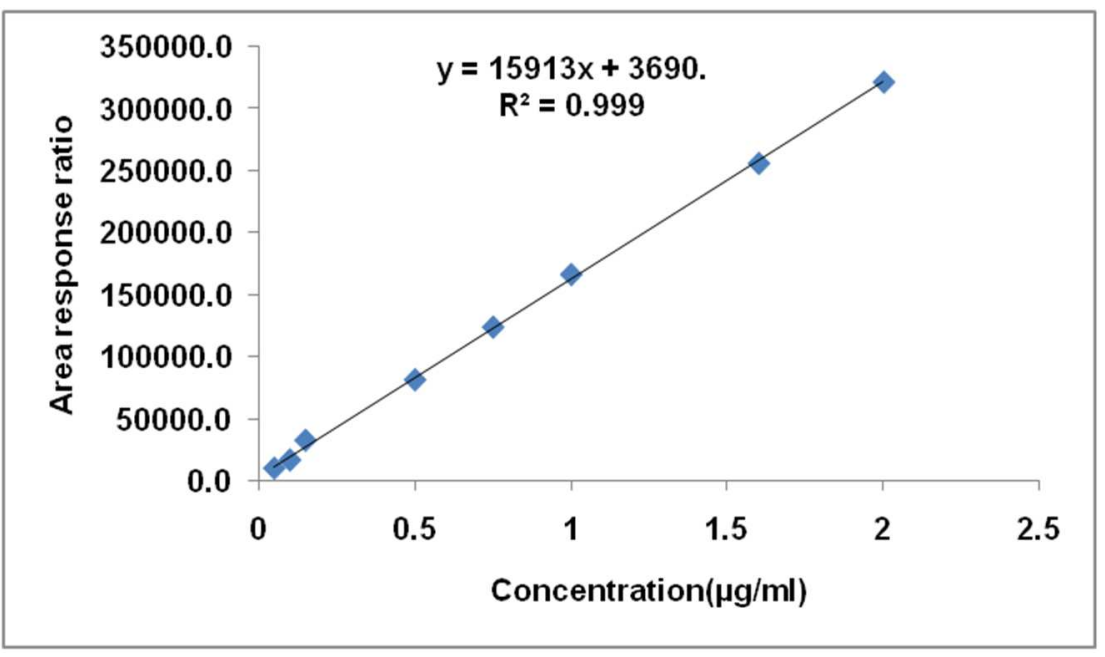

Fig. 3: A representative calibration curve of sofosbuvir 
Table 8: Long-term stability study at-80 ${ }^{\circ} \mathrm{C}(37 \mathrm{~d})$

\begin{tabular}{|c|c|c|c|c|}
\hline \multirow[t]{6}{*}{ Replicate no. } & HQC & & LQC & \\
\hline & \multicolumn{4}{|c|}{ Nominal concentration $(\mu \mathrm{g} / \mathrm{ml})$} \\
\hline & 2.000 & & 0.150 & \\
\hline & \multicolumn{4}{|c|}{ Nominal concentration range $(\mu \mathrm{g} / \mathrm{ml})$} \\
\hline & \multicolumn{2}{|l|}{$1.700-2.300$} & \multicolumn{2}{|l|}{$0.128-0.173$} \\
\hline & Comparison sample & Stability sample & Comparison sample & Stability sample \\
\hline Number of replicates & 6 & 6 & 6 & 6 \\
\hline Mean & 1.9905 & 2.0060 & 0.1508 & 0.1528 \\
\hline SD & 0.08513 & 0.06712 & 0.00828 & 0.00799 \\
\hline$\% \mathrm{CV}$ & 4.28 & 3.35 & 5.49 & 5.22 \\
\hline \%Mean accuracy & 99.53 & 100.30 & 100.56 & 101.89 \\
\hline$\%$ Mean stability & 100.78 & & 101.33 & \\
\hline
\end{tabular}

*Number of injections-6

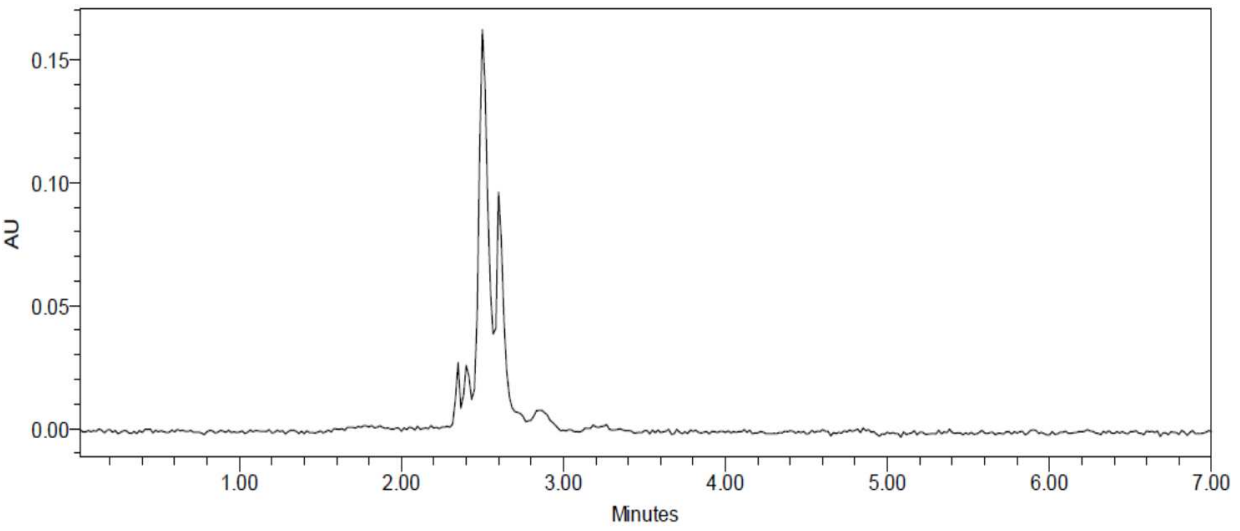

Fig. 4: A representative chromatogram of standard blank

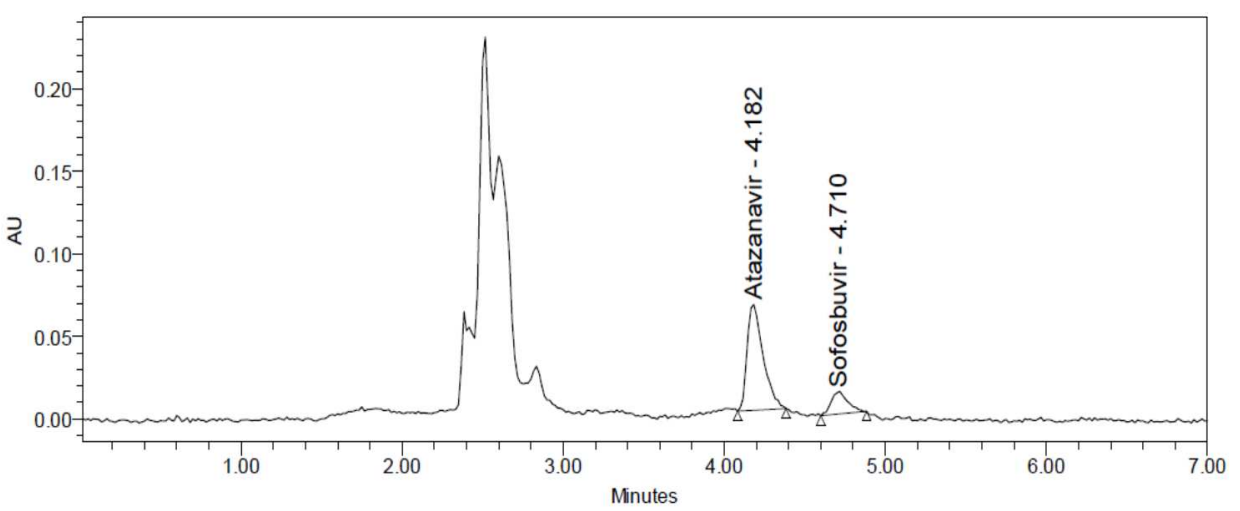

Fig. 5: A representative chromatogram of LQC

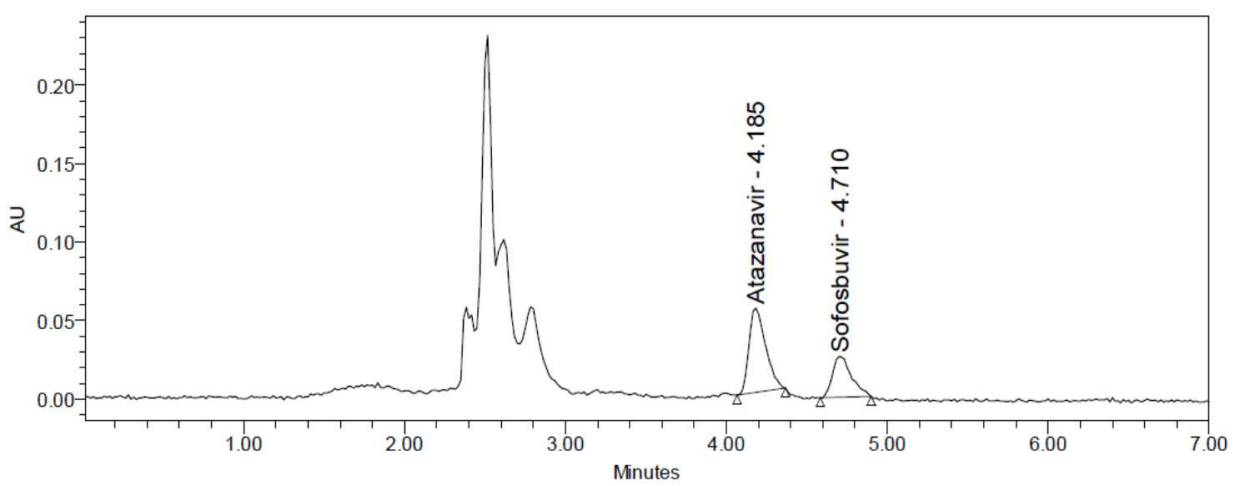

Fig. 6: A representative chromatogram of MQC 


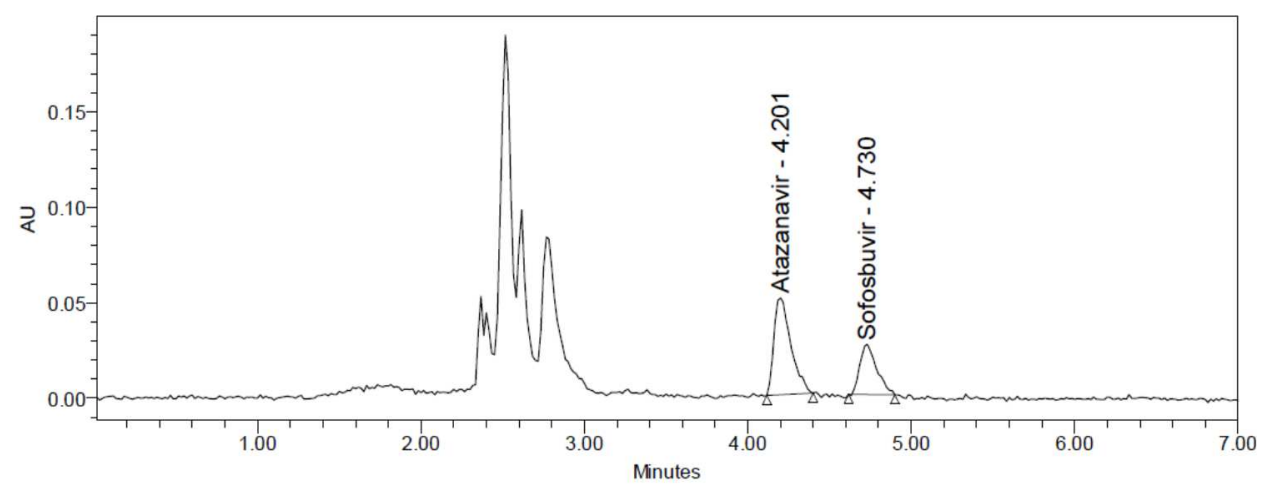

Fig. 7: A representative chromatogram of HQC

\section{CONCLUSION}

One step extraction procedure for sofosbuvir from plasma and an improved method for determination of sofosbuvir is reported. Compared to previously published methods, the suggested extraction procedure is considerably more simple, rapid, reliable and sensitive. Simple sample preparation procedure and a relatively short chromatographic time make this method suitable for processing of multiple samples in a limited amount of time for pharmacokinetic studies. The method met the validation criteria laid down by the USFDA guidelines. Hence the developed method can be applied to pharmacokinetics studies and therapeutic drug monitoring in humans.

\section{ACKNOWLEDGEMENT}

Authors are thankful for University College of Pharmaceutical Sciences, Acharya Nagarjuna University, Nagarjuna Nagar, Guntur, Andhra Pradesh, India, for providing necessary analytical facilities.

\section{CONFLICT OF INTERESTS}

Declared none

\section{REFERENCES}

1. Massimo Puoti, Claudia Panzeri, Roberto Rossotti, Chiara Baiguera. Efficacy of sofosbuvir-based therapies in HIV/HCV infected patients and persons who inject drugs. Dig Liver Dis 2014:46:206-11.

2. Marcel Nkuize, Thomas Sersté, Michel Buset, Jean-Pierre Mulkay. Combination ledipasvir-sofosbuvir for the treatment of chronic hepatitis C virus infection: a review and clinical perspective. Ther Clin Risk Manag 2016;12:861-72.

3. Ravikumar Vejendla, CVS Subramanyam. Estimation and validation of sofosbuvir in bulk and tablet dosage form by RPHPLC. Int J Pharm 2016;6:121-7.

4. Uttam Prasad Panigrahy, A Sunil Kumar Reddy. A novel validated RP-HPLC method for the simultaneous estimation of atazanavir sulphate and cobicistat in bulk and pharmaceutical dosage form. Int J Pharm Sci Rev Res 2016:36:82-9.

5. B Raj Kumar, KV Subrahmanyam. A new validated RP-HPLC method for the simultaneous determination of simeprevir and sofosbuvir in pharmaceutical dosage form. Indo Am J Pharm Sci 2016;5:4508-20.

6. Rezk MR, Basalious EB, Karim IA. Development of a sensitive UPLC-ESI-MS/MS method for quantification of sofosbuvir and its metabolite, GS-331007, in human plasma: application to a bioequivalence study. J Pharm Biomed Anal 2015:114:97-104.
7. Chenwei Pan, Yongping Chen, Weilai Chen, Guangyao Zhou. Simultaneous determination of ledipasvir, sofosbuvir and its metabolite in rat plasma by UPLC-MS/MS and its application to a pharmacokinetic study. J Chromatogr 2016;1008:255-9.

8. Michael J, Sofia. A UHPLC-MS/MS method for the quantification of direct antiviral agents simeprevir, daclatasvir, ledipasvir, sofosbuvir/GS-331007, dasabuvir, ombitasvir and paritaprevir, together with ritonavir, in human plasma. Cell 2016:16:25-9.

9. Pranay Wal, Brijesh kumar, Anil Bhandari. Bioanalytical method development determination of drugs in biological fluids. J Pharm Sci Technol 2010:2:333-47.

10. Food and drug Administration. Guidance for Industry: bioanalytical method validation. Rockville MD: US Department of Health and Human Services, Food and Drug Administration. Centre for Drug Evaluation and Research; 2001.

11. Shital Bhandari, Nikhil Khisti. Extraction less high-performance liquid chromatographic method for determination of lornoxicam in human plasma. Asian J Pharm Clin Res 2012:5:122-4.

12. Nagulu Malothu, Uday Kiran Veldandi, Rama krishna devarakonda. Development of rapid and simple HPLC method for the determination of cyclophosphamide in human serum. Asian J Pharm Clin Res 2009:2:34-8.

13. Snehal Karpe, Sandeep Sonawane, Priya Rahade, Sanjay Kshirsagar. Development and validation of a bioanalytical RPHPLC method for azilsartan medoxomil with liquid-liquid extraction. Int J Pharm Pharm Sci 2016:8:164-8.

14. Senthil Rajan, Dharmalingam, Srinivasan Ramamurthy. A simple HPLC bioanalytical method for the determination of doxorubicin hydrochloride in rat plasma: application to pharmacokinetic studies. Trop J Pharm Res 2014:13:409-15.

15. K Pushpalatha, Ramachandran. Development and validation of a RP-HPLC method for the estimation of pantoprazole. Int J Curr Pharm Res 2013:5:119-21.

16. Rutvik Pandya, Rajeshwari Rathod, Dilip Maheswari. Bioanalytical method development and validation for simultaneous determination of linagliptin and metformin drugs in human plasma by the RP-HPLC method. Pharmacophore 2014:5:202-18.

17. S Halde, A Mungantiwar, M Chintamaneni. Simple, precise and accurate HPLC method of analysis for nevirapine suspension from human plasma. Indian J Pharm Sci 2011:73:416-21.

\section{How to cite this article}

- S Madhavi, A Prameela Rani. Bioanalytical method development and validation for the determination of sofosbuvir from human plasma. Int J Pharm Pharm Sci 2017;9(3):35-41. 